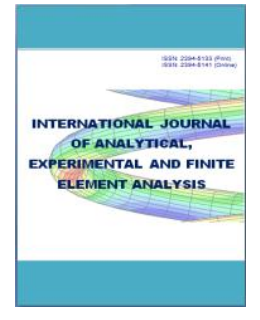

Suchita K.Khadase ${ }^{1}$ ankitakhadase12@gmail.com

Rashmi R. Gedam ${ }^{2}$ rashmig1503@gmail.com

Pragati M. Meshram ${ }^{3}$ meshrampragati@gmail.com

Premila S. Sonkusare ${ }^{4}$ premilasonkusre@gmail.com

Prof. V.P. Thakare ${ }^{5}$ vivekanand.5977@gmail.com

Suryodaya college of Engineering Computer engineering, Nagpur, India

\section{Design and Implementation of Voice Based Email Navigation System for Blinds: A Review}

Abstract - Today's communication has become so easy because of the Internet but, visually impaired people find uncomfortable to use this technology. Even though new technologies introduced to help blind people because they are not able to behave like a normal user. The aim of this paper is developing an email system that will help even blind person to use services for communication without any training. Users do not require using keyboard instead he will work only on mouse click event and speech conversion to text. The system can also be used by normal person who is not able to read. The system is based on interactive voice response (IVR).This make it user friendly and efficient.

Keywords - Listener, Visually Impaired people, IVR, Email navigation System

\section{INTRODUCTION}

The application we are devoloping is useful for Blind users for providing navigation services through Voice. Our system is cost effective. It can be installed to the desktop for Blind peoples those whoever are using computer for listning Song, read something, accesesing the information from the Internet etc. That means computers are used at every places. Blind user would not be able to write the information and cannot see the mouse cursor. This is the system through which communication is possible for email accessing to blind peoples.

\section{HELPFUl HINTS}

\section{A. System Architecture}

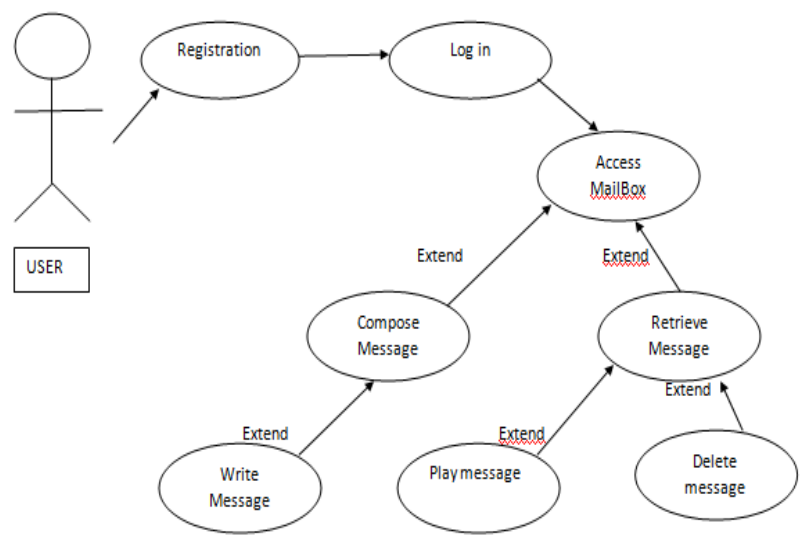

Fig 1. System architecture
If user wants to visit our software then he would have to register through the registration form. The user will be guided voice command. While registration the users have to fill the entire necessary field, by clicking on that box. The user be able to fill that box for example if user had moved cursor over register icon then it will sound "Register Button" after clicking on register button it will sound like "you are on registration page".

While filing necessary field, the speech will be recorded in the database. Very frequently words are also present when the user will speak it will be type automatically. The Voice will be recorded in database, after registration user has to login and type user id and password which will be recognize through the database. After successfull login user will read the received mail present in the inbox and also sent mail.

B. Modules and Their Working:

- Welcome Page

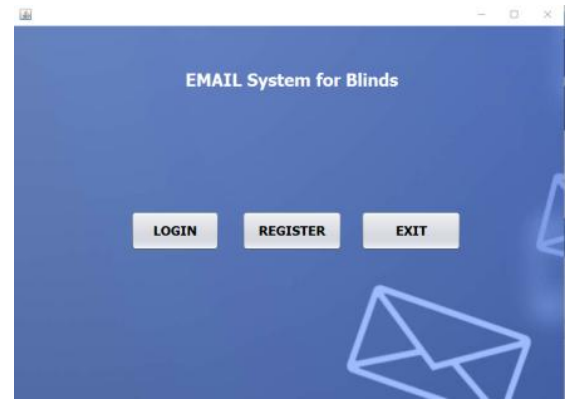

Fig. 2 Welcome Page 
This is the first page of voice based email navigation system for blinds. In that page user has three options:

Login,

Registration and

Exit.

The user can choose options from above page.

- Registration Page

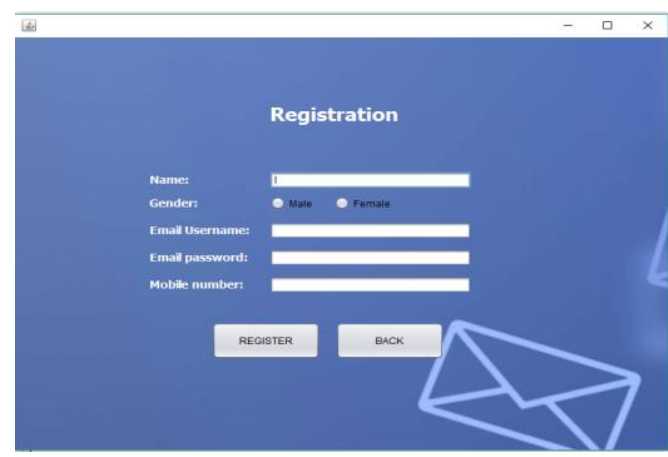

Fig. 3 Registration Page

The user can register first through the voice. The details spoken by user converted into text automatically. The user can also go back to the Welcome page.

- Login Page

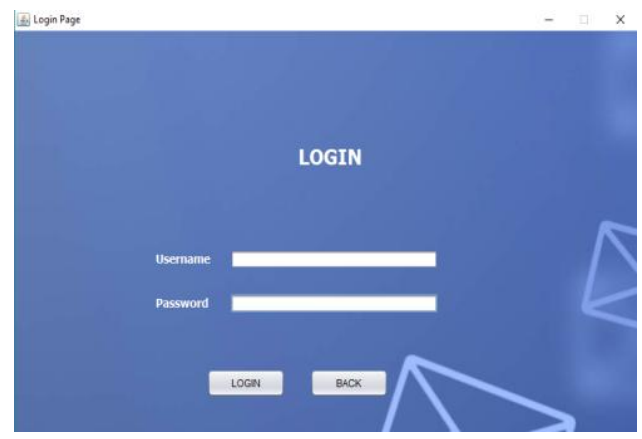

Fig. 4 Login Page

After registration user is able to login the system through username and password. The back option provided to back page to the Welcome Page.

- Home Page

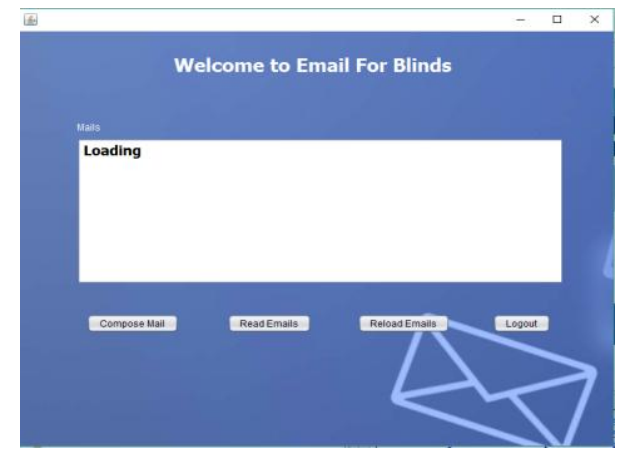

Fig.5 Home Page
After Login and Registration perform user is directed to the Home Page. The Home Page consists of following options: Compose Mail, Read Emails, Reload Emails and Exit.

- Compose Mail

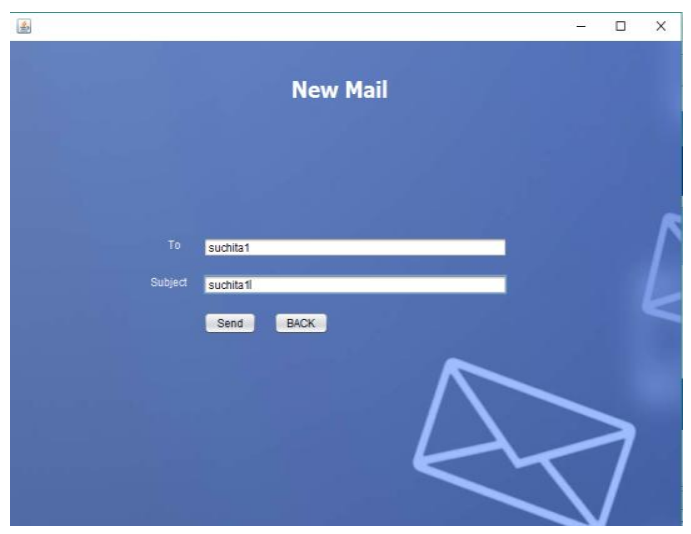

Fig.6 Compose Mail

\section{Abbreviations and Acronyms}

Three types of techniques are use in the system.

1. STT (speech to text)- Login and registration Is achieved with the help of This technology. Each and every Word user would speak Will converted into text. System présent a Small icon, after clicking that icon user's voice will converted to text format.

2. TTS (text to speech)-Text to speech is opposite to speech.In this technique text converted into text.

3. IVR (interactive voice response) - This is high level technique responsible for connecting user to the system.

\section{Equations}

- Algorithm Implementation

Consider we are given a hidden Markov model (HML) which consist of $\mathrm{S}$ state, The initial probability I of state $\mathrm{i}$ then transition probabilities from states $\mathrm{i}$ to $\mathrm{j}$. The outputs observed are $\mathrm{y}_{\mathrm{i}} \ldots \mathrm{y}_{\mathrm{T}}$. The sequence $\mathrm{x}_{\mathrm{i}} \ldots \mathrm{x}_{\mathrm{T}}$ which produce the observation is given by relation:

$$
\begin{aligned}
& \mathrm{V}_{1}, \mathrm{k}=\mathrm{P}\left(\mathrm{y}_{1} \mid \mathrm{k}\right) \cdot \pi \mathrm{k} \\
& \mathrm{V}_{\mathrm{T}}, \mathrm{k}=\max (\mathrm{x} \in \mathrm{s})\left(\mathrm{P}(\text { yeti, } \mathrm{k}) \cdot \mathrm{ax}, \mathrm{k} \cdot \mathrm{V}_{\mathrm{t}}-1, \mathrm{x}\right.
\end{aligned}
$$

$\mathrm{V}_{\mathrm{T}}, \mathrm{k}$ is the probability most probable states for first $\mathrm{t}$ that has $\mathrm{k}$ as a final states. The Viterbi path can be retrieve by saving back pointer which remembers which states are used in the second. 
Suppose $\operatorname{ptr}(k, t)$ be the function which return Value of $\mathrm{X}$ which is used to compute $\mathrm{V}_{\mathrm{T}}$, $\mathrm{k}$ if $\mathrm{t}>\mathrm{y}$ or $\mathrm{k}$ if $\mathrm{t}=1$.

\section{E. System Specification}

- Hardware Specification

$\begin{array}{llll}\checkmark & \text { Processor } & - & \text { Pentium } \\ \checkmark & \text { Speed } & - & 1.1 \mathrm{GHZ} \\ \checkmark & \text { RAM } & - & 256 \mathrm{MB}(\mathrm{min}) \\ \checkmark & \text { Hard Disk } & - & 20 \mathrm{~GB}\end{array}$

- Software Specification

$\begin{array}{lll}\checkmark & \text { Programming Language } & - \\ \checkmark & \text { JAVA } \\ & \text { Database } & \text { MySQL }\end{array}$

\section{CONCLUSION}

The project is beneficial for blind or handicap or illiterate people. User can access mail easily without any trouble the system is capable of using the advanced technology which reduce unwanted load taken by user to remember and press keys on keyboard. To the system eliminate the entire drawback which was found in accessing emails. The use of traditional screen reader also eliminated.

\section{REFERENCES}

[1] K.Jayachandran, P.Anbumani (2017) on "Voice based Email for Blind People", International Journal of Advanced Research, Ideas and Innovations in Technology (IJARIIT), pp. No. 1065-1071, Volume 3 , issue 3 .
[2] T. Shabana, A.Ananm, A.Rafiya, K.Aisha (2015) on "Voice based email system for blinds", International Journal of Advanced Research in Computer and Communication Engineering, (IJARCCE), pp No. 278-283, Volume 4, issue 1.

[3] Hari Priya S L, Karthigasree S, Revathi K(2015) on "Voice Based Email (V-Mail) for Blind", International Journal of Scientific Research and Science, Engineering and Technology (IJRSET), pp. No. 91-94, Volume 1, issue 2.

[4] Jagtap Nilesh, Pavan Alai, Chavhan Swapnil and Bendre M.R (2014) on "Voice Based System in Desktop and Mobile Devices for Blind People", International Journal of Emerging Technology and Advanced Engineering (404-407), (IJETAE, Volume 4 , issue 2).

[5] T. Dasgupta and A. Basu., "A speech enabled Indian language text to braille transliteration system", International Conference on Information and Communication Technologies and Development (ICTD), 2009, pages 201-211. IEEE, 2009.

[6] G. Shoba, G. Anusha, V. Jeevitha, R. Shanmathi , "An Interactive Email for Visually Impaired", International Journal of Advanced Research in Computer and Communication Engineering (IJARCCE), pp No. 5089-5092, Volume 3, Issue 1, 2014. 